\title{
Effect of oxide film on nanoscale mechanical removal of pure iron
}

\author{
Jinwei LIU ${ }^{1}$, Liang JIANG ${ }^{1, *}$, Changbang DENG ${ }^{1}$, Wenhao DU ${ }^{2}$, Linmao QIAN $^{1}$ \\ ${ }^{1}$ Tribology Research Institute, State Key Laboratory of Traction Power, Southwest Jiaotong University, Chengdu 610031, China \\ ${ }^{2}$ Institute of Machinery Manufacturing Technology, China Academy of Engineering Physics, Mianyang 621900, China \\ Received: 09 May 2018 / Revised: 30 July 2018 / Accepted: 02 August 2018 \\ (C) The author(s) 2018. This article is published with open access at Springerlink.com
}

\begin{abstract}
In this paper, the properties of an oxide film formed on a pure iron surface after being polished with an $\mathrm{H}_{2} \mathrm{O}_{2}$-based acidic slurry were investigated using an atomic force microscope (AFM), Auger electron spectroscopy (AES), and angle-resolved X-ray photoelectron spectroscopy (AR-XPS) to partly reveal the material removal mechanism of pure iron during chemical mechanical polishing (CMP). The AFM results show that, when rubbed against a cone-shaped diamond tip in vacuum, the material removal depth of the polished pure iron first slowly increases to $0.45 \mathrm{~nm}$ with a relatively small slope of $0.11 \mathrm{~nm} / \mu \mathrm{N}$ as the applied load increases from 0 to $4 \mu \mathrm{N}$, and then rapidly increases with a large slope of $1.98 \mathrm{~nm} / \mu \mathrm{N}$ when the applied load further increases to $10 \mu \mathrm{N}$. In combination with the AES and AR-XPS results, a layered oxide film with approximately $2 \mathrm{~nm}$ thickness (roughly estimated from the sputtering rate) is formed on the pure iron surface. Moreover, the film can be simply divided into two layers, namely, an outer layer and an inner layer. The outer layer primarily consists of FeOOH (most likely $\alpha$-FeOOH) and possibly $\mathrm{Fe}_{2} \mathrm{O}_{3}$ with a film thickness ranging from 0.36 to $0.48 \mathrm{~nm}$ (close to the $0.45 \mathrm{~nm}$ material removal depth at the $4 \mu \mathrm{N}$ turning point), while the inner layer primarily consists of $\mathrm{Fe}_{3} \mathrm{O}_{4}$. The mechanical strength of the outer layer is much higher than that of the inner layer. Moreover, the mechanical strength of the inner layer is quite close to that of the pure iron substrate. However, when a real CMP process is applied to pure iron, pure mechanical wear by silica particles generates almost no material removal due to the extremely high mechanical strength of the oxide film. This indicates that other mechanisms, such as in-situ chemical corrosion-enhanced mechanical wear, dominate the CMP process.
\end{abstract}

Keywords: oxide film; nanoscale mechanical removal; pure iron; chemical mechanical polishing

\section{Introduction}

Iron is one of the most common elements on earth. Iron-based materials such as steels and pure iron have been widely used in various high technology applications. Pure iron has been intensively used in high energy density physics [1, 2], as a liner material [3], and in some comparative experiments as a reference material [4]. In some occasions, an ultra-smooth surface with excellent surface integrity is required and is even indispensable for satisfactory device performance [5]. However, conventional ultra-precision machining techniques, such as ultra-precision cutting, may not meet such stringent requirements $[1,2,6]$. It is known that chemical mechanical polishing (CMP), which has been widely used to manufacture ultra-large scale integrated circuits, can yield an ultra-smooth surface with nano and even sub-nano surface roughness and nearly zero subsurface damage by taking advantage of the synergetic effects of chemical corrosion and mechanical wear [7-9]. Li et al. [7] fabricated a nearperfect silicon surface with $0.5 \AA$ surface roughness at the atomic scale by optimizing the CMP process. Jiang et al. [10] reported that an ultra-smooth copper

* Corresponding author: Liang JIANG, E-mail: jiangliang09@gmail.com 
surface with nearly $1 \mathrm{~nm}$ surface roughness could be obtained with the proper chemistry. Recently, Jiang et al. [11-13] extended the application of CMP to iron-based metals, including AISI 1045 steel, AISI 52100 steel, and 316L stainless steel, yielding ultra-smooth surfaces with nanoscale surface roughness. Therefore, it is feasible to obtain an ultra-smooth pure iron surface with CMP technique.

Normally, when applying CMP to metals, such as copper and iron-based metals, oxidation reactions between the metal substrate and oxidizer (such as $\mathrm{H}_{2} \mathrm{O}_{2}$ ) are indispensable to oxidize the metal to its corresponding oxidation states. The oxidized surface can subsequently react with other chemical additives, such as complexing agent, enabling effective and controllable material removal. Therefore, the oxide film formed during the polishing process via oxidation reactions is critical for polishing performance. As for copper, the copper oxide film becomes thick, dense, and passive in the presence of $\mathrm{H}_{2} \mathrm{O}_{2}$ as $\mathrm{pH}$ increases within the range of 2-10 [14]. Therefore, the material removal rate (MRR) of copper decreases. Moreover, the nanoindentation results indicate that, at $\mathrm{pH} 2$, the hardness of the film decreases significantly compared with the virgin copper surface, while no measurable effect is observed at $\mathrm{pH} 7$ or 12. This further confirms that the film formed at low $\mathrm{pH}$ is weak enough to be easily removed by mechanical abrasion. As for ironbased metals, it is revealed that the oxide film plays a significant role in material removal [11-13]. For AISI 52100 steel CMP, in the presence of glycine at $\mathrm{pH} 4.0$, the MRR first dramatically increases when $\mathrm{H}_{2} \mathrm{O}_{2}$ concentration increases from 0 to $0.01 \mathrm{wt} \%$. The result is due to formation of a porous iron oxide layer on the surface. With a further increase in $\mathrm{H}_{2} \mathrm{O}_{2}$ concentration, the MRR gradually decreases. This outcome is caused by dense growth of the porous iron oxide layer with relatively high mechanical strength via transformation of $\gamma$-FeOOH into $\alpha$-FeOOH and even into $\alpha-\mathrm{Fe}_{2} \mathrm{O}_{3}$. A similar MRR trend was observed in our preliminary results for CMP of pure iron. However, for pure iron, the properties of the oxide film formed on the top surface and its role in material removal during the CMP process remain unclear. Only a few studies showed that an oxide film with approximately $3-5 \mathrm{~nm}$ thickness is formed under different oxidation conditions [15-19]. Lin et al. [17] showed that oxide films produced by $\mathrm{O}_{2}$ exposure are predominantly trilayers of $\mathrm{FeO}, \mathrm{Fe}_{3} \mathrm{O}_{4}$, and $\mathrm{FeOOH}$ phases, wherein $\mathrm{FeOOH}$ phase is in the outermost layer. However, Bhargava et al. [15] suggested that $\mathrm{FeO}$ is unstable below $570{ }^{\circ} \mathrm{C}$, and the oxide that can coexist with iron is $\mathrm{Fe}_{3} \mathrm{O}_{4}$. Therefore, the oxide films reported by Lin et al. [17] are most likely a bilayer consisting of $\mathrm{Fe}_{3} \mathrm{O}_{4}$ and $\mathrm{FeOOH}$ phases. Dong et al. [20] studied the corrosion mechanism of mild steel, which has a similar chemical composition as pure iron, under wet/dry alternate conditions with $0.052 \mathrm{wt} \% \mathrm{NaHSO}_{3}$ solution at $\mathrm{pH}$ 4.0. The oxidation process can be divided into two stages. At the initial stage, the oxide film is porous and primarily composed of amorphous iron oxides, and small amounts of $\alpha-\mathrm{FeOOH}, \gamma-\mathrm{FeOOH}$, and $\mathrm{Fe}_{3} \mathrm{O}_{4}$. At the later stage, the content of $\alpha-\mathrm{FeOOH}$ (and even $\mathrm{Fe}_{2} \mathrm{O}_{3}$ $[16,21])$ rapidly increases as $\gamma-\mathrm{FeOOH}$ transforms into $\alpha$-FeOOH (and even $\mathrm{Fe}_{2} \mathrm{O}_{3}[16,21]$ ) when $\gamma$-FeOOH accumulates to a certain amount, and the oxide layer becomes compact [22]. Meanwhile, crystallization of $\alpha$-FeOOH can induce polymerization of the amorphous iron oxides, and the iron oxide layer becomes compact as a result [23]. Chao et al. [24] found that the addition of $\mathrm{H}_{2} \mathrm{O}_{2}$ can efficiently accelerate oxidation without changing the basic mechanism. However, a lack of studies on the oxide film formed on a pure iron surface during CMP might become an obstacle to further improving polishing performance of pure iron.

In this work, nanoscale mechanical removal of a pure iron sample polished with an $\mathrm{H}_{2} \mathrm{O}_{2}$-based acidic slurry was investigated using an atomic force microscope (AFM) with a cone-shaped diamond tip and an $\mathrm{SiO}_{2}$ microsphere tip in vacuum. The chemical composition of the polished pure iron surface was subsequently characterized using Auger electron spectroscopy (AES) and angle-resolved X-ray photoelectron spectroscopy (AR-XPS). Based on the above results, the effect of the oxide film on nanoscale mechanical removal of pure iron was discussed.

\section{Material and methods}

Experimental samples with a size of $10 \mathrm{~mm} \times 10 \mathrm{~mm} \times$ $2 \mathrm{~mm}$ were first cut from a large piece of polycrystalline pure iron (DT4E) and were polished using a UNIPOL802 desktop polisher with a designated $\mathrm{H}_{2} \mathrm{O}_{2}$-based acidic slurry. The samples were subsequently rinsed 
with deionized (DI) water, dried with nitrogen, and then immediately placed into a vacuum chamber to avoid further oxidation and contamination. After applying the above treatments, the arithmetic average surface roughness $\left(R_{\mathrm{a}}\right)$ over a $2 \mu \mathrm{m} \times 2 \mu \mathrm{m}$ area reduced from its initial value of $122.4 \pm 48.6 \mathrm{~nm}$ to $0.31 \pm 0.07 \mathrm{~nm}$, and an ultra-smooth surface was obtained. The samples were subsequently used for AFM, AES, and AR-XPS tests. The polishing slurry was composed of $4 \mathrm{wt} \%$ NexSil 85K colloidal silica (purchased from Nyacol Nano Technologies, Inc., $50 \mathrm{~nm}$ primary particle size), $0.01 \mathrm{wt} \% \mathrm{H}_{2} \mathrm{O}_{2}$ (reagent grade, purchased from Sinopharm Chemical Reagent Co., Ltd) and DI water at $\mathrm{pH}$. The polishing conditions were set as follows: 6.4 psi down force, $200 \mathrm{rpm}$ table speed, $25 \mathrm{~mL} / \mathrm{min}$ slurry flow rate, and $5 \mathrm{~min}$ polishing time. An IC1010/Sub-IV composite pad was used. Between each polishing, ex-situ pad conditioning was performed for $2 \mathrm{~min}$ to deglaze the pad surface.

To study the nanoscale mechanical removal behavior of pure iron, wear tests of the polished pure iron sample against a cone-shaped diamond tip (NC-LC, Adama, Ireland, $100 \mathrm{~N} / \mathrm{m}$ spring constant) were carried out using an AFM (SPA-300HV/SPI3800N Probe Station, Seiko, Japan) in vacuum at room temperature under the following experimental conditions: $2-10 \mu \mathrm{N}$ applied load $F_{\mathrm{N}}, 0.5 \mu \mathrm{m} / \mathrm{s}$ relative sliding velocity $v, 1 \mu \mathrm{m}$ relative sliding length $L$, and 1 number of reciprocating sliding cycles $N$. All wear tests were repeated at least three time to ensure the results were reproducible. Figure 1 illustrates the nanoscale wear tests conducted within one crystalline grain of pure iron. As shown in the inset of Fig. 1, the radius of the diamond tip is approximately dozens of nanometers, which is consistent with the nominal value. After the wear tests, a silicon nitride AFM probe (MSCT, Bruker, USA) with less than $20 \mathrm{~nm}$ nominal radius of curvature was used to scan the 3D surface topography of the experimental area. In order to determine the exact wear area, a microhardness tester was used to indent an L-shape maker on the pure iron surface before conducting the wear tests. The marker has five points in each direction with an interval of $50 \mu \mathrm{m}$ between each point. All the points can be clearly observed with a light microscope. Based on the relative location in the L-shape coordinate system, the exact wear area can be easily identified.

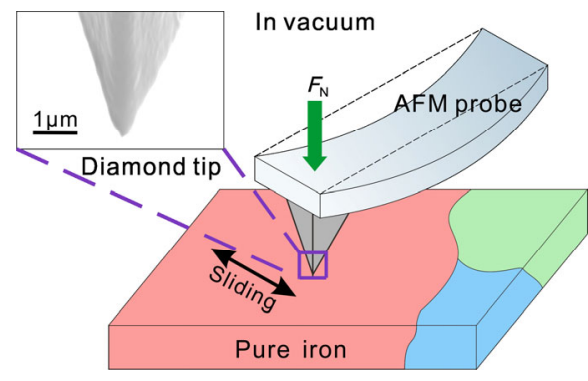

Fig. 1 Schematic of the nanoscale wear tests conducted within one crystalline grain of pure iron. The inset shows a scanning electron microscopy image of the cone-shaped diamond tip.

To comparatively study the effect of the oxide film, a dilute $\mathrm{HCl}$ solution was used to obtain an oxidefree pure iron surface by removing the initial oxide film. The polished pure iron sample was first dipped into a dilute $\mathrm{HCl}$ solution at $\mathrm{pH} 1.5$ for $30 \mathrm{~s}$ and was then washed, dried, and placed into a vacuum chamber for wear tests against a cone-shaped diamond tip under the same experimental conditions as the polished pure iron sample. The $R_{\mathrm{a}}$ value for the $\mathrm{HCl}$-treated pure iron surface over a $2 \mu \mathrm{m} \times 2 \mu \mathrm{m}$ area was $4.51 \pm 0.29 \mathrm{~nm}$.

To further reveal the effect of the oxide film on the material removal of pure iron in a real CMP process, similar wear tests of the polished pure iron sample against a chemically active $\mathrm{SiO}_{2}$ microsphere tip of $2.5 \mu \mathrm{m}$ diameter (Novascan Technologies, Inc., $16 \mathrm{~N} / \mathrm{m}$ spring constant) were carried out in vacuum at room temperature under the following experimental conditions: $4 \mu \mathrm{N}$ applied load $F_{\mathrm{N}}, 0.5 \mu \mathrm{m} / \mathrm{s}$ relative sliding velocity $v, 1 \mu \mathrm{m}$ relative sliding length $L$, and 100, 300, 500 , and 1000 numbers of reciprocating sliding cycles $N$ separately.

The chemical composition of the polished pure iron surface was characterized using AES and AR-XPS. The sample was first degaussed before being transferred to the chamber in order to avoid negative measurement effects. AES was used to quantitatively analyze the chemical depth profile at the sample surface. The measurements were performed using a PHI-700 Scanning Auger Nanoprobe (ULVAC-PHI, Japan) with a $5 \mathrm{kV}$ coaxial electron gun and a cylindrical mirror energy analyzer. In addition, the energy resolution was $1 \%$, the incidence angle was $30^{\circ}$, the vacuum chamber pressure was less than $3.9 \times 10^{-9}$ Torr, and a scanning $\mathrm{Ar}^{+}$gun was used to sputter depth profiling. AR-XPS was used to characterize the chemical 
composition of the sample surface at different depths. The measurements were carried out using a PHI Quantera SXM (ULVAC-PHI, Japan) with a hemispherical energy analyzer and a monochromatic aluminum target. The X-ray beam spot size was $200 \mu \mathrm{m}$, and the analysis chamber pressure was less than $1.0 \times 10^{-7}$ Torr. By rotating the sample, spectra were obtained at four different photoelectron take-off angles from the surface $\left(5^{\circ}, 25^{\circ}, 55^{\circ}\right.$, and $\left.85^{\circ}\right)$. Here, the take-off angle is the angle between the sample surface and the photoelectron emission direction [15]. The XPS detection depth increases as the take-off angle increases, and thereby the chemical composition at different depths can be acquired. High-resolution spectra corresponding to $\mathrm{Fe}$ and $\mathrm{O}$ were obtained using $55 \mathrm{eV}$ pass energy with $0.1 \mathrm{eV}$ step size. The data was then analyzed with CasaXPS software.

\section{Results and discussion}

\subsection{Nanoscale mechanical removal behavior of pure iron with an oxide film}

A thin oxide film inevitably forms on the top surface of pure iron during the polishing process due to oxidation reactions between $\mathrm{H}_{2} \mathrm{O}_{2}$ and pure iron. Typical AFM surface topographical images and average cross-section profiles of the material removal traces after wear tests against the diamond tip are shown in Fig. 2. Corresponding statistical data showing the amount of removed material, including the material removal depth $d$ and the material removal volume $V$, are shown in Fig. 3. Assuming that no material removal occurs when the applied load is zero in vacuum, the material removal depth slowly increases linearly with a relatively small slope of $0.11 \mathrm{~nm} / \mu \mathrm{N}$ as the applied load increases from 0 to $4 \mu \mathrm{N}$. Specifically, at $2 \mu \mathrm{N}$, an extremely shallow groove-like scratch with a depth of $0.2 \mathrm{~nm}$ starts to form on the surface. The depth increases to $0.45 \mathrm{~nm}$ at $4 \mu \mathrm{N}$. A turning point emerges at $4 \mu \mathrm{N}$. When the applied load further increases from 4 to $10 \mu \mathrm{N}$, unlike the preceding trend, the material removal depth rapidly increases from 0.45 to $11.83 \mathrm{~nm}$ with a large slope of $1.98 \mathrm{~nm} / \mu \mathrm{N}$. At $10 \mu \mathrm{N}$, an apparent scratch with a depth of $11.83 \mathrm{~nm}$ can be observed on the surface. The material removal volume shares a similar trend with the material

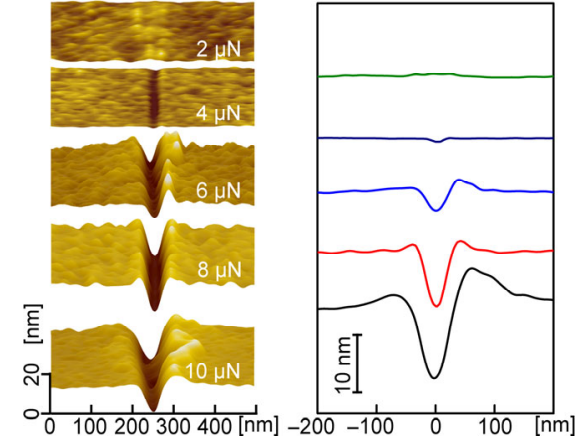

Fig. 2 Typical AFM surface topographical images and average cross-section profiles of the material removal traces after performing wear tests on the polished pure iron surface against a diamond tip in vacuum.
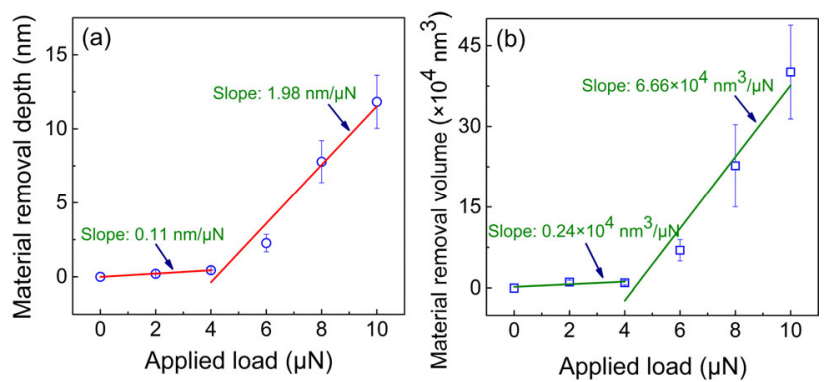

Fig. 3 Corresponding statistical data for the amount of removed material after performing wear tests on the polished pure iron surface against a diamond tip in vacuum. (a) Material removal depth $d$. (b) Material removal volume $V$.

removal depth, except for the slope. The difference in the slopes can be attributed to the influence of the nonuniform cross-section area along the depth. Based on the existence of a turning point at $4 \mu \mathrm{N}$, one can infer that the polished pure iron surface is layered, probably due to the formation of the oxide film, and the resultant mechanical strength is inhomogeneous along the depth direction. Moreover, the top layer exhibits high mechanical strength since the slope of the amount of removed material versus the applied load is initially small.

\subsection{Nanoscale mechanical removal behavior of oxide-free pure iron}

To verify the above inference on the oxide film, the polished pure iron sample was etched with a dilute $\mathrm{HCl}$ solution to obtain an oxide-free surface and was subsequently rubbed against the diamond tip. Typical AFM surface topographical images and average crosssection profiles of the material removal traces after the wear tests are shown in Fig. 4(a). The correspon- 

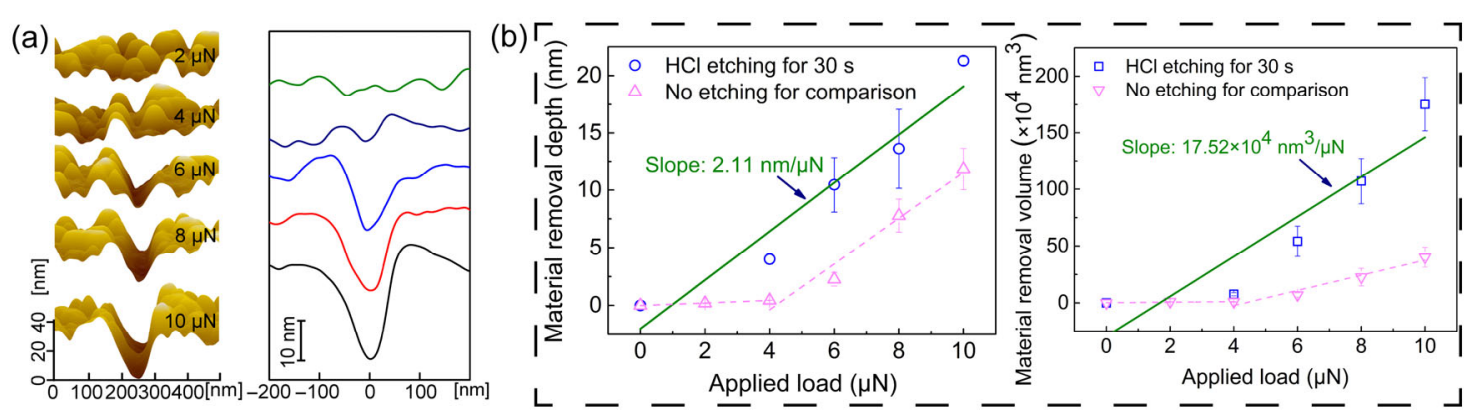

Fig. 4 (a) Typical AFM surface topographical images and average cross-section profiles of the material removal traces after performing wear tests on the oxide-free pure iron surface treated with a dilute $\mathrm{HCl}$ solution at $\mathrm{pH} 1.5$ against a diamond tip in vacuum. (b) Corresponding statistical data for the amount of removed material and comparison with the results of the polished pure iron sample as presented in Fig. 3.

ding statistical data showing the amount of removed material are shown and compared with the data from the polished pure iron sample in Fig. 4(b). As shown in Fig. 4(a), the surface treated with the dilute $\mathrm{HCl}$ solution becomes much rougher compared with the polished pure iron surface, which is probably due to nonuniform etching by hydrogen ions. As seen from Fig. 4(b), the material removal depth and material removal volume almost linearly increase with slopes of $2.11 \mathrm{~nm} / \mu \mathrm{N}$ and $17.52 \times 10^{4} \mathrm{~nm}^{3} / \mu \mathrm{N}$, respectively, based on linear fitting when the applied load increases from 0 to $10 \mu \mathrm{N}$. This assumes that no material removal occurs at $0 \mu \mathrm{N}$ and also the result at $2 \mu \mathrm{N}$ is excluded since it is almost impossible to identify the scratch due to the relatively rough surface. No turning point emerges throughout the test range, unlike the trend for the polished pure iron sample. This result indicates that the mechanical strength of the oxide-free pure iron surface is quite homogeneous along the depth direction. Moreover, by removing the oxide film, the amount of removed material apparently increases probably due to a much lower mechanical strength of the pure iron substrate compared with the oxide film. Therefore, the oxide film formed on the pure iron surface results in inhomogeneous mechanical strength, which can be roughly divided into two parts. The higher strength portion is near the top of the film, as indicated by the initial relatively small slope for the amount of removed material versus the applied load. However, whether the boundary between the two regions with different mechanical strengths is situated within the oxide film or in between the oxide film and the pure iron substrate remains unclear.

\subsection{Characterization of oxide film formed on pure iron surface}

To determine the boundary, AES and AR-XPS tests were carried out to characterize the chemical composition and structure of the oxide film formed on the pure iron surface. The AES depth profiles of the oxide film after polishing are shown in Fig. 5(a). The corresponding AES spectra before and after sputtering for 3 min are shown in Fig. 5(b). In general, the typical depth probed by AES is approximately $2 \mathrm{~nm}$ [25]. The reference sputtering rate of $\mathrm{SiO}_{2}$ is $2 \mathrm{~nm} / \mathrm{min}$. Baera et al. $[26,27]$ reported that the average value of relative sputter ratio of $\mathrm{Fe}_{2} \mathrm{O}_{3}$ to $\mathrm{SiO}_{2}$ is 0.61 with 0.06 standard deviation. This data is used to roughly estimate the thickness of the pure iron oxide film in our experiment. Based on the criterion where AES depth profiles at a point where the oxygen concentration becomes near zero and stable, the total oxide film thickness can be estimated to be approximately $2 \mathrm{~nm}$. When the sputtering time increases from 0 to $0.3 \mathrm{~min} / 0.4 \mathrm{~min}$, the concentration of iron on the exposed pure iron surface increases from 37.8 at $\%$ to 42.4 at $\% / 43.6$ at $\%$, and the $\mathrm{Fe} / \mathrm{O}$ ratio increases from 0.61 to $0.74 / 0.77$, indicating that the remaining oxide film can be primarily composed of $\mathrm{Fe}_{3} \mathrm{O}_{4}$ since the $\mathrm{Fe} / \mathrm{O}$ ratio of $\mathrm{Fe}_{3} \mathrm{O}_{4}$ is $0.75[15,17]$. Moreover, the sputtered oxide film can be primarily composed of ferric oxides, such as $\mathrm{FeOOH}$ and $\mathrm{Fe}_{2} \mathrm{O}_{3}[16,17,21]$ with a film thickness ranging from 0.36 to $0.48 \mathrm{~nm}$. The thickness of ferric oxides film is quite consistent with the observed $0.45 \mathrm{~nm}$ material removal depth at the aforementioned $4 \mu \mathrm{N}$ turning point from the polished pure iron sample. When the sputtering time increases further, 

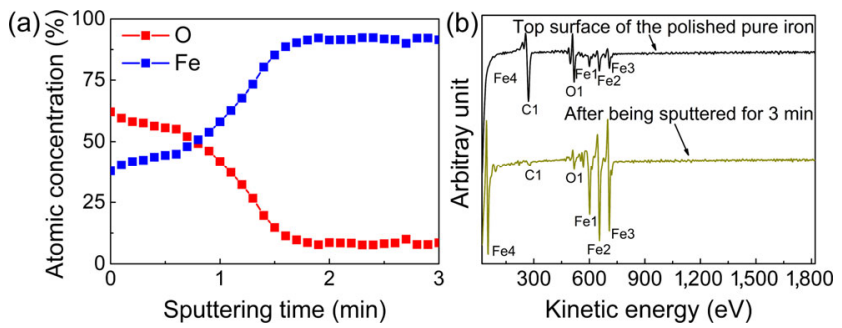

Fig. 5 (a) AES depth profiles of the oxide film formed on the top surface of pure iron after being polished with the $\mathrm{H}_{2} \mathrm{O}_{2}$-based acidic slurry. (b) Corresponding AES spectra before and after sputtering for $3 \mathrm{~min}$.

the concentration of iron on the exposed pure iron surface continuously increases and then stabilizes, which suggests that the oxide film gradually transitions to the pure iron substrate underneath. As shown in Fig. 5(b), the atomic concentration of iron becomes much larger after being sputtered for $3 \mathrm{~min}$.

AR-XPS was used to further analyze the chemical composition of the oxide film. The experimental sample was the same as that in the AES measurement. The corresponding $\mathrm{O}(1 \mathrm{~s})$ spectra, which were obtained at four different photoelectron take-off angles $\left(5^{\circ}, 25^{\circ}\right.$, $55^{\circ}$, and $85^{\circ}$ ) are shown in Fig. 6. Deconvolution of the $\mathrm{O}(1 \mathrm{~s})$ spectra reveals two peaks at approximately $530.1 \mathrm{eV}$ and $531.5 \mathrm{eV}$, which correspond to oxygen as forms of $\mathrm{O}^{2-}$ and $\mathrm{OH}^{-}$, respectively [15]. Moreover, the proportion of oxygen as $\mathrm{OH}^{-}$gradually decreases from 70.1 at $\%$ to 47.9 at $\%$ as the photoelectron take-off angle increases from $5^{\circ}$ to $85^{\circ}$, which indicates that $\mathrm{OH}^{-}$exists in the outer layer of the oxide film. The
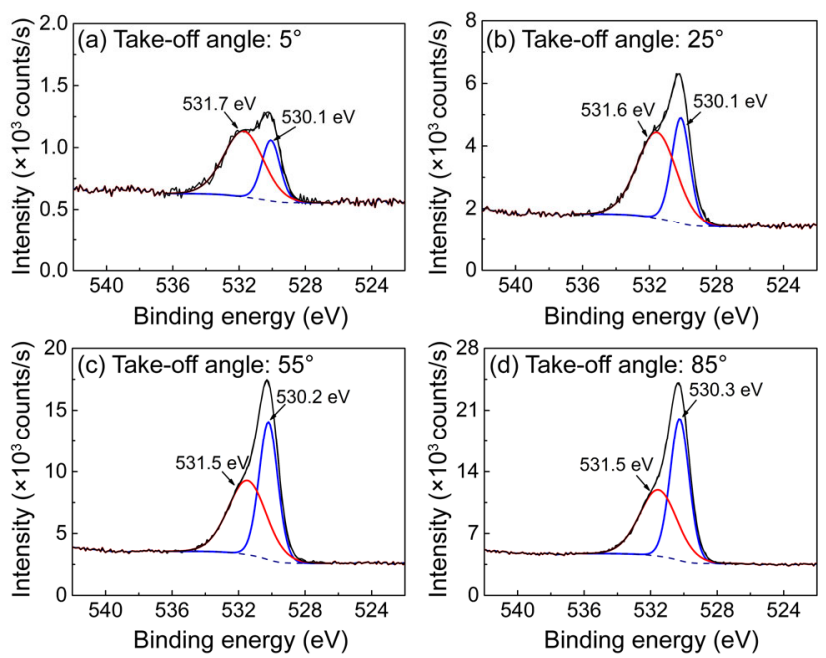

Fig. 6 XPS O(1s) spectra of the polished pure iron surface obtained at four different photoelectron take-off angles. corresponding $\mathrm{Fe}(2 \mathrm{p})$ spectra are shown in Fig. 7. Deconvolution of the $\mathrm{Fe}(2 \mathrm{p})$ spectra reveals two peaks. Specifically, the peak with the low binding energy corresponds to iron as a form of metallic iron, and the peak with the high binding energy corresponds to iron as a form of a mixture of ferric and ferrous oxides [15]. In addition, as the photoelectron take-off angle increases from $5^{\circ}$ to $85^{\circ}$, the proportion of iron as metallic iron gradually increases from almost 0 to 16.8 at $\%$. The XPS signal of metallic iron is probably derived from the pure iron substrate underneath the oxide film.

\subsection{Effect of oxide film on nanoscale mechanical removal of pure iron}

Based on the above results, one can conclude that a thin oxide film with approximately $2 \mathrm{~nm}$ thickness (roughly estimated from the sputtering rate) formed on the pure iron surface after being polished with the $\mathrm{H}_{2} \mathrm{O}_{2}$-based acidic slurry. According to the AES and AR-XPS results, the oxide film can be roughly divided into an outer layer and an inner layer, as shown in Fig. 8. Any intermediate layer is ignored. The thickness of the outer layer ranges from 0.36 to $0.48 \mathrm{~nm}$ (roughly estimated from the sputtering rate) and is primarily composed of $\mathrm{FeOOH}$ (most likely $\alpha$-FeOOH) and possibly $\mathrm{Fe}_{2} \mathrm{O}_{3}$, while the inner layer is primarily composed of $\mathrm{Fe}_{3} \mathrm{O}_{4}$ [15-17]. In accordance with the proposed bilayer oxide film structure, one can find that the boundary between the two regions with
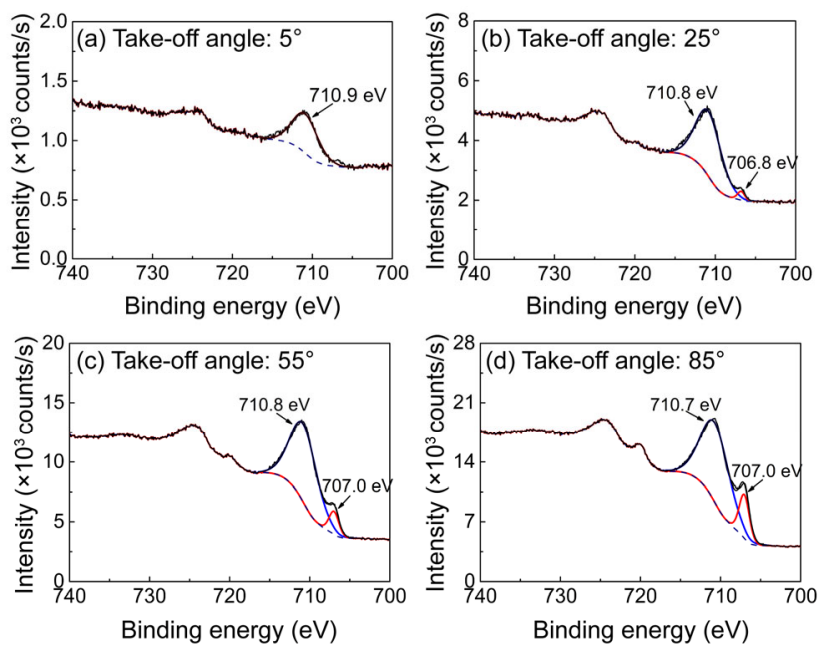

Fig. 7 XPS $\mathrm{Fe}(2 \mathrm{p})$ spectra of the polished pure iron surface obtained at four different photoelectron take-off angles. 


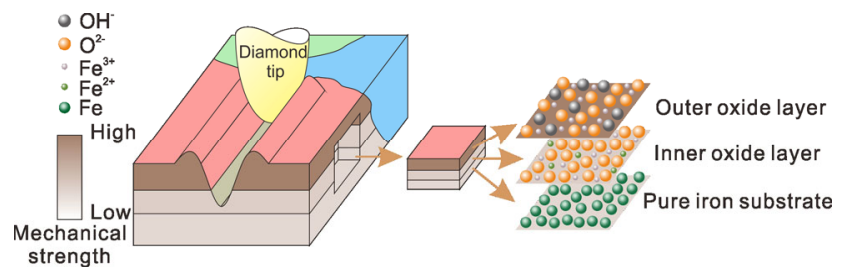

Fig. 8 Schematic illustration demonstrating the effect of the oxide film on nanoscale mechanical removal of pure iron.

different mechanical strengths is situated within the oxide film and in between the outer and inner layers, given the fact that the thickness of the outer layer agrees well with the $0.45 \mathrm{~nm}$ material removal depth at the $4 \mu \mathrm{N}$ turning point from the polished pure iron sample. Moreover, based on the AFM results, the mechanical strength of the outer layer of the oxide film is much larger than those of the inner layer and the pure iron substrate, possibly due to the increased compactness induced by crystallization of $\alpha-\mathrm{FeOOH}$ $[20,22,23]$. In addition, the mechanical strength of the inner layer is quite close to that of the pure iron substrate since the amount of removed material increases linearly without any distinct turning point when the applied load increases from 4 to $10 \mu \mathrm{N}$ until the material removal depth reaches $11.83 \mathrm{~nm}$ at $10 \mu \mathrm{N}$, which is far beyond the oxide film thickness [28].

As for real CMP of iron-based metals, colloidal silica is widely used as an abrasive to obtain an ideal ultra-smooth surface without micro scratches [29]. Our preliminary CMP results show that the MRR of pure iron can reach as high as $163 \mathrm{~nm} / \mathrm{min}$ when being polished with the slurry containing $4 \mathrm{wt} \%$ colloidal silica, $0.01 \mathrm{wt} \% \mathrm{H}_{2} \mathrm{O}_{2}$, and DI water at $\mathrm{pH} 4$ under the aforementioned polishing conditions. However, no material is removed when the polished pure iron surface is rubbed against a $\mathrm{SiO}_{2}$ microsphere tip at 1.15 GPa contact pressure (according to Hertz contact theory) in vacuum, even after applying 1000 reciprocating sliding cycles, as shown in Fig. 9. This result is due to the extremely high mechanical strength of the oxide film formed on the pure iron surface compared with that of $\mathrm{SiO}_{2}$. The wear tests results indicate that other mechanisms, such as in-situ chemical corrosion-enhanced mechanical wear, control material removal during CMP. Furthermore, one possible mechanism is that $\mathrm{H}_{2} \mathrm{O}_{2}$ in the acidic slurry will react with ferric ions near the surface to form ferrous ions.

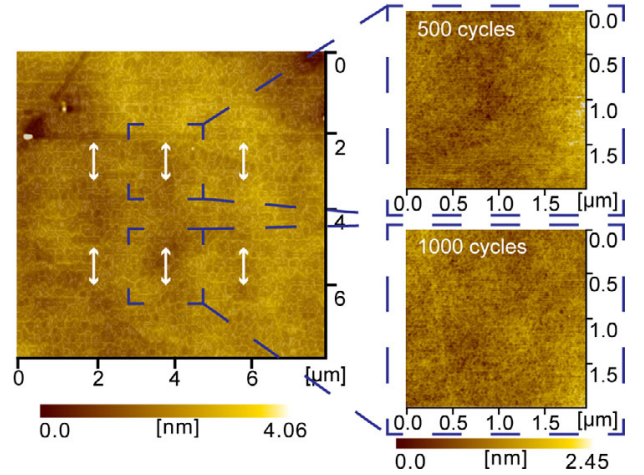

Fig. 9 Typical AFM surface topographical images after performing wear tests on the polished pure iron surface against a $\mathrm{SiO}_{2}$ microsphere tip in vacuum.

As a result, either the resultant reactivity of the surface will be improved, or the resultant mechanical strength of the surface will be reduced, or both. More investigation is ongoing so that the material removal mechanism during the CMP process can be better understood.

\section{Conclusions}

The mechanical properties of the oxide film formed on the pure iron surface after being polished with the slurry containing $0.01 \mathrm{wt} \% \mathrm{H}_{2} \mathrm{O}_{2}$ at $\mathrm{pH} 4.0$ were investigated using an AFM against the diamond tip in vacuum. The chemical composition and structure of the oxide film were characterized using AES and AR-XPS. The conclusions are summarized as follows:

(1) A thin oxide film with approximately $2 \mathrm{~nm}$ thickness is formed on the pure iron surface after being polished with the $\mathrm{H}_{2} \mathrm{O}_{2}$-based acidic slurry. The oxide film is layered and can be roughly divided into an outer layer and an inner layer. The outer layer has a thickness ranging from 0.36 to $0.48 \mathrm{~nm}$ (close to the $0.45 \mathrm{~nm}$ material removal depth at the $4 \mu \mathrm{N}$ turning point) is primarily composed of $\mathrm{FeOOH}$ (most likely $\alpha$-FeOOH) and possibly $\mathrm{Fe}_{2} \mathrm{O}_{3}$, whereas the inner layer is primarily composed of $\mathrm{Fe}_{3} \mathrm{O}_{4}$. Moreover, the mechanical strength of the outer layer is much larger than the strength of the inner layer and the pure iron substrate. The mechanical strength of the inner layer is quite close to that of the pure iron substrate.

(2) With respect to real CMP of pure iron, given the fact that the mechanical strength of the oxide film is extremely high compared with that of colloidal silica, 
pure mechanical wear with colloidal silica generates almost no material removal. This phenomenon indicates that, from the view of mechanical removal, the oxide film functions as a handicap. Moreover, other mechanisms, such as in-situ chemical corrosionenhanced mechanical wear, dominate the entire CMP process. The results provide insight into how CMP affects pure iron, suggesting that it is important to select proper chemical additives, such as $0.01 \mathrm{wt} \%$ $\mathrm{H}_{2} \mathrm{O}_{2}$, to promote in-situ chemical corrosion and obtain an ultra-smooth surface with high removal efficiency.

\section{Acknowledgements}

The authors are grateful for the financial support provided by the National Natural Science Foundation of China (No. 51605396), Young Elite Scientists Sponsorship Program by CAST (No. YESS20160056), Science Challenge Project (No. TZ2018006-0101-04), and Selfdeveloped Project of State Key Laboratory of Traction Power (No. 2017TPL_Z02).

Open Access: The articles published in this journal are distributed under the terms of the Creative Commons Attribution 4.0 International License (http://creativecommons.org/licenses/by/4.0/), which permits unrestricted use, distribution, and reproduction in any medium, provided you give appropriate credit to the original author(s) and the source, provide a link to the Creative Commons license, and indicate if changes were made.

\section{References}

[1] Kong J X, Deng F, Zhao W, He N. Effects of cooling/ lubrication conditions on surface integrity of pure iron materials during turning. (in Chinese). Journal of South China University of Technology (Natural Science Edition) 43(6): 89-95 (2015)

[2] Kong J X, Hu K, Xia Z H, Li L. Effects of tool wear on surface integrity of pure iron material under finish turning. (in Chinese). Journal of South China University of Technology (Natural Science Edition) 44(2): 74-80 (2016)

[3] Li W-B, Wang X-M, Zhou H. Effect of the liner material on the shape of dual mode penetrators. Combustion, Explosion, and Shock Waves 51(3): 387-394 (2015)

[4] Pérez Escobar D, Miñambres C, Duprez L, Verbeken K,
Verhaege M. Internal and surface damage of multiphase steels and pure iron after electrochemical hydrogen charging. Corros Sci 53(10): 3166-3176 (2011)

[5] Jia W, Zhang Q, Bai Z, Ma S, Yao D, Wang Y. Progress on manufacturing techniques of shaped charge liners. (in Chineses). Rare Metal Materials and Engineering 36(9): 1511-1516 (2007)

[6] Massarelli L, Marchionni M. Morphology of spark-affected surface layers produced on pure iron and steels by electrodischarge machining. Metals Technology 4(1): 100-105 (1977)

[7] Li J, Liu Y H, Dai Y J, Yue D C, Lu X C, Luo J B. Achievement of a near-perfect smooth silicon surface. Science China Technological Sciences 56(11): 2847-2853 (2013)

[8] Li Y. Microelectronic Applications of Chemical Mechanical Planarization. Wiley-Interscience, USA, 2007.

[9] Babu S. Advances in Chemical Mechanical Planarization (CMP). Woodhead Publishing, 2016.

[10] Jiang L, Lan Y, He Y, Li Y, Luo J. Functions of Trilon ${ }^{\circledR} \mathrm{P}$ as a polyamine in copper chemical mechanical polishing. Appl Surf Sci 288: 265-274 (2014)

[11] Jiang L, He Y, Luo J. Effects of $\mathrm{pH}$ and oxidizer on chemical mechanical polishing of AISI 1045 steel. Tribol Lett 56(2): 327-335 (2014)

[12] Jiang L, He Y, Luo J. Chemical mechanical polishing of steel substrate using colloidal silica-based slurries. Appl Surf Sci 330: 487-495 (2015)

[13] Jiang L, He Y, Yang Y, Luo J. Chemical mechanical polishing of stainless steel as solar cell substrate. ECS Journal of Solid State Science and Technology 4(5): P162-P170 (2015)

[14] Du T, Desai V. Chemical mechanical planarization of copper: pH effect. J Mater Sci Lett 22(22): 1623-1625 (2003)

[15] Bhargava G, Gouzman I, Chun C M, Ramanarayanan T A, Bernasek S L. Characterization of the "native" surface thin film on pure polycrystalline iron: A high resolution XPS and TEM study. Appl Surf Sci 253(9): 4322-4329 (2007)

[16] Grosvenor A P, Kobe B A, McIntyre N S, Tougaard S, Lennard W N. Use of QUASES ${ }^{\mathrm{TM}} / \mathrm{XPS}$ measurements to determine the oxide composition and thickness on an iron substrate. Surf Interface Anal 36(7): 632-639 (2004)

[17] Lin T-C, Seshadri G, Kelber J A. A consistent method for quantitative XPS peak analysis of thin oxide films on clean polycrystalline iron surfaces. Appl Surf Sci 119(1): 83-92 (1997)

[18] Mathieu H J, Datta M, Landolt D. Thickness of natural oxide films determined by AES and XPS with/without sputtering. Journal of Vacuum Science \& Technology A: Vacuum, Surfaces, and Films 3(2): 331-335 (1985)

[19] Stambouli V, Palacio C, Mathieu H J, Landolt D. Comparison of in-situ low-pressure oxidation of pure iron at room 
temperature in $\mathrm{O}_{2}$ and in $\mathrm{O}_{2} / \mathrm{H}_{2} \mathrm{O}$ mixtures using XPS. Appl Surf Sci 70-71: 240-244 (1993)

[20] Dong J, Dong J, Han E, Liu C, Ke W. Rusting evolvement of mild steel under wet/dry cyclic condition with $\mathrm{pH} 4.00$ $\mathrm{NaHSO}_{3}$ solution. (in Chinese). Corrosion Science and Protection Technology 21(1): 1-4 (2009)

[21] Miyazawa T, Terachi T, Uchida S, Satoh T, Tsukada T, Satoh Y, Wada Y, Hosokawa H. Effects of hydrogen peroxide on corrosion of stainless steel, (V) characterization of oxide film with multilateral surface analyses. $J \mathrm{Nucl} \mathrm{Sci}$ Technol 43(8): 884-895 (2006)

[22] Wang J J, Guo X D, Zheng W L, Chen J G, Wu J S. Analysis of the corrosion rust on weathering steel and carbon steel exposed in marine atmosphere for three years. (in Chinese). Corrosion \& Protection 23(7): 288-291 (2002)

[23] Junhua D, Wei K. The accelerated test of simulated atmospheric corrosion and the rust evolution of low carbon steel. (in Chinese). Electrochemistry 15(2): 170-178 (2009)

[24] Chao Y, Huixia Z, Weimin G, Yubin F. Effects of $\mathrm{H}_{2} \mathrm{O}_{2}$ addition on corrosion behavior of high-strength low-alloy steel in seawater. (in Chinese). Journal of Chinese Society for Corrosion and Protection33(003): 205-210 (2013)

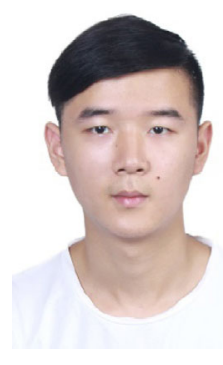

Jinwei LIU. He received his bachelor degree in mechanical engineering in 2016 from Southwest Jiaotong University, Chengdu, China. He is

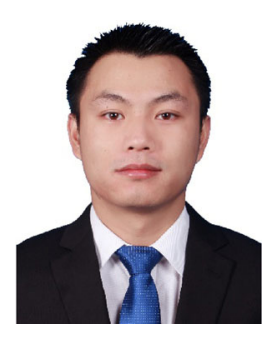

Liang JIANG. He is an associate professor in mechanical engineering at Southwest Jiaotong University, Chengdu, China. He received his bachelor degree in mechanical engineering in 2009 from Harbin Institute of Technology, Harbin,
[25] Brundle C R, Evans C A, Wilson S. Encyclopedia of Materials Characterization: Surfaces, Interfaces, Thin Films. Gulf Professional Publishing, 1992.

[26] Baer D R, Engelhard M H, Gaspar D J, Matson D W, Pecher K H, Williams J R, Wang C M. Challenges in applying surface analysis methods to nanoparticles and nanostructured materials. Journal of Surface Analysis 12(2): 101-108 (2005)

[27] Baera D R, Engelhard M H, Lea A S, Nachimuthu P. Comparison of the sputter rates of oxide films relative to the sputter rate of $\mathrm{SiO}_{2}$. Journal of Vacuum Science \& Technology A 28(5): 1060-1072 (2010)

[28] Chicot D, Mendoza J, Zaoui A, Louis G, Lepingle V, Roudet F, Lesage J. Mechanical properties of magnetite $\left(\mathrm{Fe}_{3} \mathrm{O}_{4}\right)$, hematite $\left(\alpha-\mathrm{Fe}_{2} \mathrm{O}_{3}\right)$ and goethite $(\alpha-\mathrm{FeO} \cdot \mathrm{OH})$ by instrumented indentation and molecular dynamics analysis. Mater Chem Phys 129(3): 862-870 (2011)

[29] Kao M J, Hsu F C, Peng D X. Synthesis and characterization of $\mathrm{SiO}_{2}$ nanoparticles and their efficacy in chemical mechanical polishing steel substrate. Advances in Materials Science and Engineering 2014: 1-8 (2014)

currently a PhD candidate in Tribology Research Institute at the same university. His research interest includes metal materials chemical mechanical polishing.

China, and his $\mathrm{PhD}$ degree in mechanical engineering in 2015 from Tsinghua University, Beijing, China. During the period 2010-2012, he studied as a joint PhD student in Clarkson University, Potsdam, NY, USA. After then, he joined the faculty at Southwest Jiaotong University in 2015. His research interest includes chemical mechanical polishing. 